\title{
Anesthesia for cesarean section in a patient with respiratory failure
}

\section{-A case report-}

\author{
Hae Jin Lee, Jin Young Chon, Hyun-Jung Koh, Noh-Su Park, and Ji-Young Lee \\ Department of Anesthesiology and Pain Medicine, Yeouido St. Mary's Hospital, The Catholic University of Korea College of Medicine, \\ Seoul, Korea
}

We present successful epidural anesthesia and assisted mechanical ventilation in a parturient woman with respiratory failure. A 41-year-old woman at 35 weeks' of gestation was entering labor. She was pneumonectomized on the left, had bronchiectasis on the remnant lung, and was under assisted mechanical ventilation by continuous positive airway pressure (CPAP) because of severely restricted lung function and superimposed pneumonia. We administered continuous epidural analgesia for vaginal delivery, and extended it for cesarean section after failure of vaginal delivery. During the procedure, her ventilation was continuously assisted by CPAP. The maternal and fetal outcomes were successful. (Korean J Anesthesiol 2013; 64: 460-463)

Key Words: Cesarean section, Continuous positive airway pressure, Epidural anesthesia, Respiratory failure.

In a study of obstetric patients requiring intensive care unit (ICU) admission, mechanical ventilation was used in $41 \%$ of patients, most often for acute respiratory failure and hemodynamic failure [1]. Several cases of anesthesia for delivery in women with respiratory failure were reported [24]. An anesthesiologist should consider the types and drugs of anesthesia, level of regional anesthesia, and support of perioperative ventilatory care. This case report describes the anesthetic course in a pregnant patient with respiratory failure who presented for vaginal delivery and cesarean section. She had severely restricted lung function from tuberculosisdestroyed lung, left pneumonectomy, bronchiectasis on the remnant lung, and superimposed pneumonia. We reviewed anesthetic management of patients with respiratory failure during labor.

\section{Case Report}

A 41-year-old woman at 35 weeks' gestation was referred to Department of Anesthesia for analgesia during vaginal delivery. She was $160 \mathrm{~cm}$ tall and weighed $57 \mathrm{~kg}$. She suffered from tuberculous pleurisy at 11 years old, diagnosed with tuberculosis-induced destroyed lung at 20 years old, and finally got left pneumonectomy at 25 years old. After the surgery,

Received: June 12, 2012. Revised: 1st, July 17, 2012; 2nd, August 2, 2012. Accepted: August 3, 2012.

Corresponding author: Ji-Young Lee, M.D., Department of Anesthesiology and Pain Medicine, Yeouido St. Mary's Hospital, The Catholic University of Korea College of Medicine, 62, Yeouido-dong, Yeongdeungpo-gu, Seoul 150-713, Korea. Tel: 82-2-3779-1944, Fax: 82-2-783-0368, E-mail: leeji@catholic.ac.kr

(C)This is an open-access article distributed under the terms of the Creative Commons Attribution Non-Commercial License (http:// creativecommons.org/licenses/by-nc/3.0/), which permits unrestricted non-commercial use, distribution, and reproduction in any medium, provided the original work is properly cited. 
remnant right lung was bronchiectatic. She had frequent respiratory failure due to respiratory infections and was treated by intermittent admission with mechanical ventilation. At the early period of this admission, due to pneumonia on right lower lobe followed by respiratory failure, she was ventilated mechanically via endotracheal tube. Soon after, she got tracheostomy for prolonged mechanical ventilation. The lowest $\mathrm{PaO}_{2}$ checked during that period was $36.9 \mathrm{mmHg}$. It was difficult for her to be weaned from mechanical ventilation after recovery from acute pneumonia, so her ventilation was supported by synchronized intermittent mandatory ventilation (SIMV) or continuous positive airway pressure (CPAP). At 3 months after admission, she was diagnosed as 20 weeks' gestation. The patient elected to continue pregnancy, despite medical warning against influences of prior frequent maternal hypoxemia and heavy medications on fetus, increasingly difficult ventilatory management as she was approaching confinement. She stayed at ICU during rest period of pregnancy with ventilatory support by CPAP. At 35 weeks' gestation, the obstetrician decided to induce delivery, and injected misoprostol $50 \mu \mathrm{g}$ subcutaneously at 4 hour intervals. Her chest x-ray showed tuberculous scar at right upper lung field, compensatory emphysematous change of whole right lung combined to left pneumonectomy state (Fig. 1). The last arterial blood gas analysis (ABGA) before onset of labor showed pH 7.362, $\mathrm{PaCO}_{2} 49.3 \mathrm{mmHg}, \mathrm{PaO}_{2} 241.4 \mathrm{mmHg}, \mathrm{HCO}_{3}{ }^{-}$ $27.7 \mathrm{mmol} / \mathrm{L}$, and $99.8 \%$ of oxygen saturation, while the patient was under assisted ventilation with $\mathrm{CPAP}$ at $\mathrm{FiO}_{2}$ 0.6. Pulmonary function test was not available. Her hemoglobin value was 10.8 $\mathrm{g} / \mathrm{dl}$. The blood chemistry showed hypoalbuminemia (albumin

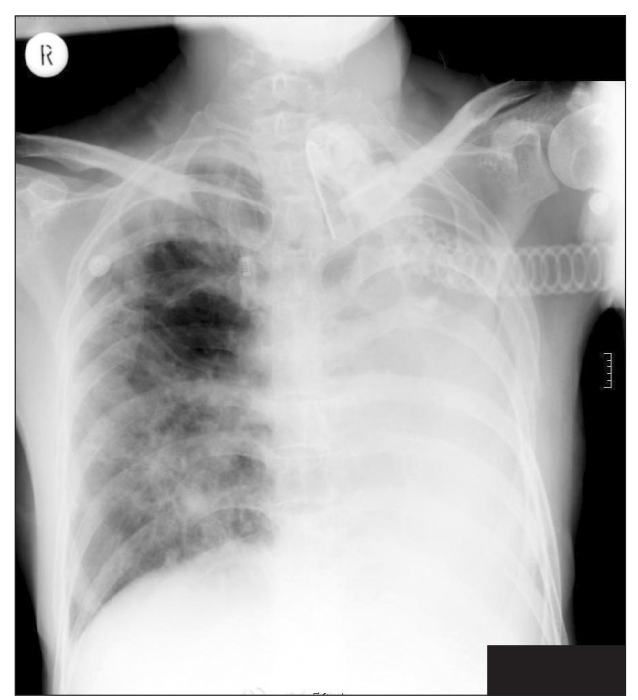

Fig. 1. Preoperative chest AP shows left pneumonectomy state and compensatory emphysematous change of right lung. Tuberculous scar at right upper lung field and infiltrative lesion at middle and lower lobe can be seen. Tracheostomy tube is located in trachea.
$2.99 \mathrm{~g} / \mathrm{dl}$ ), but other laboratory findings were normal.

We conducted epidural anesthesia with 17-gauge Tuohy needle at L3-4 epidural space by midline approach at lateral position, and inserted a 20-gauge epidural catheter to cephalad. We injected $15 \mathrm{ml}$ of $0.125 \%$ bupivacaine and fentanyl $20 \mu \mathrm{g}$ via epidural catheter. A sensory level to T8 was achieved at 15 min after epidural block. Patient controlled epidural analgesia (PCEA) was applied with initial setting as continuous infusion of $0.125 \%$ bupivacaine $5 \mathrm{ml} / \mathrm{hr}$. The bolus injection dose and lockout interval were set to $5 \mathrm{ml}$ and $5 \mathrm{~min}$ each, under the control of an anesthesiologist responsible for extending the level of sensory block. Fetal heart rate and uterine contraction were monitored continuously. Because delivery could not be induced by regular injection of misoprostol for two days, elective cesarean section was decided to be performed on the third day from epidural anesthesia. We stopped PCEA and discussed the methods of anesthesia and possible complications with the patient and obstetrician. Both general and epidural anesthesia were easily performed because the patient already had a tracheostomy tube and an epidural catheter. But, the patient strongly refused to be ventilated with control mode ventilation (CMV) under general anesthesia. To be precise, she refused to be paralyzed by neuromuscular blocking agent due to fear of difficult weaning from CMV. The extension of epidural anesthesia up to T4 sensory level through epidural catheter and application of CPAP were planned. On the other hand, we also warned the patient that the level of anesthesia could be incomplete or excessive, and we would have to perform general anesthesia in that situation.

The patient was transported to operative suite with $5 \mathrm{~L} / \mathrm{min}$ of supplementary oxygen through catheter into the tracheostomy tube. As soon as she arrived at operating room, we connected the anesthetic circuit to tracheostomy tube and applied $8 \mathrm{cmH}_{2} \mathrm{O}$ of positive airway pressure with $40 \%$ of oxygen in air while the patient breathed spontaneously. The monitoring consisted of electrocardiography, noninvasive blood pressure, arterial oxygen saturation by pulse oximetry $\left(\mathrm{SpO}_{2}\right)$. Her initial blood pressure was $130 / 80 \mathrm{mmHg}$, with heart rate of 75 beats/min and $\mathrm{SpO}_{2} 97 \%$. After checking patency of the epidural catheter and confirming no bloody aspirates with saline-filled syringe, we injected $15 \mathrm{ml}$ of $2 \%$ lidocaine and $50 \mu \mathrm{g}$ of fentanyl through the epidural catheter. Over the next 10 minutes, additional $10 \mathrm{ml}$ of $1.5 \%$ lidocaine was injected epidurally to achieve a level of $\mathrm{T} 4$ sensory block to cold. As soon as such a level confirmed, cesarean section was started. A male infant weighing $2.53 \mathrm{~kg}$ was delivered within 5 minutes with Apgar scores of 7 and 8 at 1 and $5 \mathrm{~min}$. We injected ephedrine $5 \mathrm{mg}$ intravenously to compensate for hypotension post birth. Total operative duration was 35 minutes and total anesthetic duration was 55 minutes. The result of ABGA after baby birth 
showed pH of 7.425, $\mathrm{PaCO}_{2} 40.0 \mathrm{mmHg}, \mathrm{PaO}_{2} 169 \mathrm{mmHg}$, $\mathrm{HCO}_{3}{ }^{-} 27.7 \mathrm{mmol} / \mathrm{L}$, and $99.2 \%$ of oxygen saturation. A total $900 \mathrm{ml}$ of Ringer's lactate solution was infused and the patient tolerated well the anesthesia and operation. Blood loss was approximately $500 \mathrm{ml}$. After completion of cesarean section, we removed the epidural catheter after injection of morphine 3 mg. She was transported to ICU while ventilated mechanically. While in the ICU, her ventilation was assisted with CPAP at the level of pressure support $8 \mathrm{cmH}_{2} \mathrm{O}$ with $\mathrm{FiO}_{2}$ 0.4. Her vital signs and ventilation parameters were stable. The ABGA showed $\mathrm{pH}$ of 7.446, $\mathrm{PaCO}_{2} 39.7 \mathrm{mmHg}, \mathrm{PaO}_{2} 32.3 \mathrm{mmHg}, \mathrm{HCO}_{3}{ }^{-} 27.0$ $\mathrm{mmol} / \mathrm{L}$, and $98.4 \%$ of oxygen saturation. After 2 days, weaning from ventilator was started, but it took 30 days. She was discharged at 77 days after cesarean section with home oxygen supplement.

\section{Discussion}

Anesthetic management of pregnant women with respiratory failure poses special problems. The most important problem is reduction in oxygen delivery to the fetus [5]. Anesthesiologists will try to keep oxygen delivery to the fetus while manage ventilation of mother. The choices of anesthetic methods and drugs require great care.

For the vaginal delivery, we selected an epidural technique with PCEA. Lumbar epidural anesthesia is known to provide pain relief without neonatal respiratory depression or reduced oxygen consumption [6]. Because the patient with respiratory failure used accessory muscles for respiration, neuraxial anesthesia might disturb the mechanics of breathing, but could provide anesthesia, reduce oxygen consumption, extend duration of analgesia, and expand the range of anesthesia for cesarean section without heavy motor block.

For cesarean section, it should be easy to perform general anesthesia with mechanical ventilation for better control of gas exchange and tracheobronchial toilet, because the patient had tracheostomy tube already. From another perspective, general anesthesia could impair matching of ventilation - perfusion in patients with pulmonary diseases. It could be a reason that anesthesiologists induce regional anesthesia instead of general anesthesia in those patients [7]. Also, there was a possibility that we might need to change the mode of mechanical ventilation, with a patient who strongly refused to be ventilated by control mode. Since we already placed an epidural catheter, we tried to satisfy the patient's wishes by choosing extension of epidural anesthesia.

To avoid a too extensive block that might impair respiratory function, but to provide adequate anesthesia for cesarean section, we tried to expand epidural anesthesia level to T4. Howell et al. [8] recommended a maximum block level to T6 for cesarean section in patients with cystic fibrosis to lessen the risks of respiratory embarrassment, but they did not comment which method they used to discern the level of blockade. Cameron and Skinner. [3] extended the level of anesthesia to T3 by a loss of temperature sensation and $\mathrm{T} 8$ by pinprick sensation. The patients tolerated this well, like our patient. Though we used $0.125 \%$ bupivacaine for labor analgesia during vaginal delivery, a more potent drug was suitable for epidural anesthesia for cesarean section. Our choice was epidural injection of $2 \%$ lidocaine followed by $1.5 \%$ lidocaine to reduce total dose, and $50 \mu \mathrm{g}$ of fentanyl for intense blockade. In previous case reports, other authors used $0.5 \%$ bupivacaine, $0.75 \%$ ropivacaine, or $1.5-2 \%$ lidocaine $[3,4,8]$. The reason we used lidocaine was to hasten delivery for the needs of the patient and obstetricians who worried about welfare of the baby because of changing fetal heart patterns. In spite of our concern about epidural fentanyl causing respiratory depression, it was not harmful for mother and baby.

Considering that pulmonary sympathetic efferents emerge from the spinal cord between T2 and T7 [9], our epidural anesthesia might block T4-T7 sympathetic nerves. But, it was known that segmental high thoracic epidural anesthesia alone increases neither airway resistance at rest nor bronchial reactivity to acetylcholine [10]. Other researchers [11] have found that segmental high thoracic anesthesia from $\mathrm{C} 4$ to $\mathrm{T} 8$ or T9 significantly decreased forced expiratory volume at 1 second $\left(\mathrm{FEV}_{1}\right)$, but increased forced expiratory volume at 1 second over vital capacity. Consequently, epidural anesthesia producing sympathetic blockade can be used in patients with severe obstructive pulmonary disease. Also, amide local anesthetics absorbed from epidural space attenuated bronchial hyperreactivity dose dependently [12].

We decided to remove the epidural catheter after cesarean section because three days had passed after placement. Instead of PCEA, we used epidural morphine which the patient tolerated well.

Like prior reports that anesthesiologists used non-invasive positive pressure ventilation for managing the pregnant patients with respiratory failure [2,4], we applied CPAP to our patient continuously through tracheostomy tube during cesarean section under epidural anesthesia. We conclude that cesarean section under epidural anesthesia in a patient with respiratory failure is relatively safe when assisted mechanical ventilation is used continuously.

\section{References}

1. Vasquez DN, Estenssoro E, Canales HS, Reina R, Saenz MG, Das Neves AV, et al. Clinical characteristics and outcomes of obstetric patients requiring ICU admission. Chest 2007; 131: 718-24. 
2. Kähler CM, Högl B, Habeler R, Brezinka C, Hamacher J, Dienstl A, et al. Management of respiratory deterioration in a pregnant patient with severe kyphoscoliosis by non-invasive positive pressure ventilation. Wien Klin Wochenschr 2002; 114: 874-7.

3. Cameron AJ, Skinner TA. Management of a parturient with respiratory failure secondary to cystic fibrosis. Anaesthesia 2005; 60: 77-80.

4. Bose D, Yentis SM, Fauvel NJ. Caesarean section in a parturient with respiratory failure caused by cystic fibrosis. Anaesthesia 1997; 52: 578-82.

5. Catanzarite V, Willms D, Wong D, Landers C, Cousins L, Schrimmer D. Acute respiratory distress syndrome in pregnancy and the puerperium: causes, courses, and outcomes. Obstet Gynecol 2001; 97: 760-4.

6. Ackerman WE 3rd, Molnar JM, Juneja MM. Beneficial effect of epidural anesthesia on oxygen consumption in a parturient with adult respiratory distress syndrome. South Med J 1993; 86: 361-4.

7. Lee EY, Kong MH, Kim NS, Lim SH, Lee MK, Lee IO, et al. Epidural anesthesia for a cesarean section in a parturient patient with congestive heart failure and respiratory insufficiency. Korean J
Anesthesiol 2007; 53: 656-9.

8. Howell PR, Kent N, Douglas MJ. Anaesthesia for the parturient with cystic fibrosis. Int J Obstet Anesth 1993; 2: 152-8.

9. Bonica JJ. Autonomic innervation of the viscera in relation to nerve block. Anesthesiology 1968; 29: 793-813.

10. Gruber EM, Tschernko EM, Kritzinger M, Deviatko E, Wisser W, Zurakowski D, et al. The effects of thoracic epidural analgesia with bupivacaine $0.25 \%$ on ventilatory mechanics in patients with severe chronic obstructive pulmonary disease. Anesth Analg 2001; 92: 1015-9.

11. Groeben H, Schäfer B, Pavlakovic G, Silvanus MT, Peters J. Lung function under high thoracic segmental epidural anesthesia with ropivacaine or bupivacaine in patients with severe obstructive pulmonary disease undergoing breast surgery. Anesthesiology 2002; 96: 536-41.

12. Groeben H, Schwalen A, Irsfeld S, Stieglitz S, Lipfert P, Hopf HB. Intravenous lidocaine and bupivacaine dose-dependently attenuate bronchial hyperreactivity in awake volunteers. Anesthesiology 1996; 84: 533-9. 